\title{
Joggin' the Noggin: Towards a Physiological Understanding of Exercise-Induced Cognitive Benefits
}

\author{
Nikolas J. Stimpson \\ Faculty of Mathematical and Physical Sciences, University College London, UK \\ nikolas.stimpson.12@alumni.ucl.ac.uk
}

\section{Glen Davison}

School of Sport \& Exercise Sciences, University of Kent, UK

g.davison@kent.ac.uk

\section{Amir-Homayoun Javadi*}

School of Psychology, University of Kent, UK

Institute of Behavioural Neuroscience, Department of Experimental Psychology, University College London, UK

a.h.javadi@gmail.com

+441227827770

Address:

School of Psychology

Keynes College

University of Kent

Canterbury, CT2 7NP

United Kingdom

* corresponding author

Conflict of Interest: The authors declare that they have no conflict of interest. 


\section{Background}

There is considerable evidence that physical exercise has beneficial effects on multiple cognitive domains, particularly executive functions (Babaei et al. 2013; Best et al. 2014; Chang et al. 2012; Colcombe and Kramer 2003; Davis et al. 2011; Dupuy et al. 2015; Hillman et al. 2008; Lee et al. 2014; Predovan et al. 2012). Furthermore, exercise may be protective against the cognitive decline and neurodegeneration observed in normal ageing (Barnes et al. 2004; Colcombe et al. 2004; Dupuy et al. 2015; Erickson et al. 2011; Hill et al. 1993; Holzschneider et al. 2012; Prakash et al. 2015). Themanson and Hillman (2006) suggest that such effects may be driven by exercise-related improvements in cardiorespiratory fitness. Cardiovascular fitness, a subset of cardiorespiratory fitness, is positively associated with cognitive functioning in several domains (Brown et al. 2010; Colcombe et al. 2004; Dupuy et al. 2015; Hötting et al. 2012; Hyodo et al. 2015; Kawagoe et al. 2017; Voelcker-Rehage et al. 2010; but compare Etnier et al. 2006; Young et al. 2015). Exercise that causes an increase in cardiovascular fitness (e.g. whole body aerobic exercise such as running, cycling, or walking) generally has more significant effects on cognition and brain structure than exercise focussed on enhancing strength, such as resistance training (Colcombe et al. 2004; Colcombe et al. 2006; Dustman et al. 1984; Erickson et al. 2011; Kramer et al. 1999; Leckie et al. 2014; Struthers et al. 2017).

Thus, it appears plausible that a physiological mechanism unique to exercise yielding cardiovascular fitness improvements exists that can also yield selective neurocognitive benefits. Although not capturing all aspects of fitness, fitness is often determined by measuring pre- and post- intervention changes in maximal oxygen consumption $\left(\mathrm{VO}_{2} \mathrm{max}\right)$ reached during a graded exercise test. This review will provide an overview of research in this field and assess four claims comprising a possible causal pathway for cognitive benefits induced by aerobic exercise: a) cardiovascular fitness promotes cerebral angiogenesis and circulation; b) improved cerebral circulation is related to 
increased neurotrophin delivery and neurogenesis; c) this neurotrophin delivery contributes to the functional enhancement of neurons; and d) these enhanced neurons are sensitive to domain-specific cognitive training. While previous reviews and metaanalyses have examined the individual effects of exercise on angiogenesis, cerebral blood volume, upregulation of neurotrophins, neurogenesis, and cognition (e.g. Colcombe and Kramer 2003; Hillman et al. 2008; Smith et al. 2011; Voss et al. 2013), here we describe how these mechanisms might interact with each other and the approximate time scale of each mechanism. We also draw attention to the apparent necessity of angiogenesis and domain-specific cognitive training in this process for yielding optimal cognitive benefits from exercise interventions.

\section{Cardiovascular Fitness Promotes Cerebral Angiogenesis and Circulation}

Cerebral angiogenesis has been associated with cerebral blood volume (CBV) (Maia et al. 2005). Pereira et al. (2007) demonstrated that three months of aerobic exercise causes increased neurogenesis and CBV in the dentate gyrus (DG) of the human hippocampus, and the increased $\mathrm{CBV}$ was correlated with improved $\mathrm{VO}_{2}$ max and verbal recall. They suggested angiogenesis as a possible intermediary between exercise-induced increases in CBV and neurogenesis. Maass et al. (2015) also observed increased CBV in the hippocampus following a three-month aerobic exercise intervention, and this increase was associated with improved performance on recognition and spatial memory tasks. Further demonstrating that exercise-induced angiogenesis occurs in the brain and not just skeletal muscle, exercise has been found to induce angiogenesis in the rat frontoparietal cortex (Ding et al. 2006), motor cortex (Ding et al. 2006; Kleim et al. 2002; Swain et al. 2003), striatum (Ding et al. 2006), cerebellum (Black et al. 1990; Isaacs et al. 1992), and the mouse hippocampus (Morland et al. 2017). Exercise also promotes endothelial cell proliferation in the rat hippocampus (Ekstrand et al. 2008). Overall, it appears that 
cardiovascular fitness promotes angiogenesis in the brain, and this yields improved cerebral circulation. The mechanisms for this may be related to an upregulation of gene expression for the chemokine CXCL12 (also known as SDF-1). This is observed after three weeks of exercise in mouse models of Alzheimer's disease (Parachikova et al. 2008); CXCL12 participates in angiogenesis by acting as a chemical attractor for endothelial cells (Salcedo et al. 1999). Exercise has been shown to promote both endothelial progenitor cells (EPCs) and the endothelial nitric oxide synthase (eNOS) enzyme in mice (Gertz et al. 2006). eNOS-produced nitric oxide has antioxidant effects (Fukai et al. 2000) and is important for maintenance of the vascular endothelium (Förstermann and Münzel 2006). Exercise-induced eNOS upregulation also promotes angiogenesis (Gertz et al. 2006); taken together, it seems likely that eNOS also serves to enhance the neurogenic niche. Similarly, the expression of forkhead box transcription factors that inhibit angiogenesis (FOXO1 and FOXO3a) is repressed by chronic exercise (Slopack et al. 2014; see Sanchez 2015 for review).

Following the notion that cognitive benefits of cardiovascular health could be attributed to improved cerebral oxygenation, Dupuy et al. (2015) found $\mathrm{VO}_{2}$ maxassociated improvements in executive functions for young (ages 19 - 34 years old) and older (ages 55 - 72 years old) women. In particular they found that those with higher $\mathrm{VO}_{2}$ max measurements demonstrated greater changes in cerebral blood oxygenation during testing. That individuals who are less fit and who engage in less exercise did not see such circulatory changes, would indicate that aerobic exercise, which generally leads to higher cardiovascular fitness, contributes to circulation and its apparent effect on task performance. Dupuy et al. (2015) also acknowledge the possibility that individuals with lower cardiovascular fitness may have a larger stress response to cognitively demanding tasks, and that the associated sympathetic nervous system activation could negatively affect cerebral oxygenation, hence resulting in poorer cognitive performance. It could be expected that in some cases this poorer performance will amplify the stress response, forming a negative feedback loop. Of course, intense exercise also elicits a stress 
response; the difference between a harmful and a beneficial stress response may lie in the regulation of certain hormones and neurotrophins (see below). In any case, though research is still in its early stages, there is thus far a general consensus that cerebral blood perfusion improves with cardiovascular fitness (likely via angiogenesis and endothelial support) and this positively affects cognitive task performance.

\section{Exercise-induced Upregulation of Neurotrophins}

Several neurotrophins seem to be particularly affected by physical activity. Brainderived neurotrophic factor (BDNF), a neurotrophin critically involved in memory that supports neuronal development (Bekinschtein et al. 2008; Huang and Reichardt 2001), appears upregulated by short- and long-term exercise in the rat hippocampus, caudal neocortex, and spinal cord (Aguiar et al. 2011; Berchtold et al. 2005; Gómez-Pinilla et al. 2002; Neeper et al. 1995; Soya et al. 2007; Vaynman et al. 2004), and also in the mouse hippocampus and striatum (Aguiar et al. 2008; Johnson et al. 2003; Lafenêtre et al. 2010; Marlatt et al. 2012). BDNF is released from synaptic structures in the brain (Hartmann et al. 2001; Kojima et al. 2001; see Leßmann and Brigadski 2009 for review), and stored within platelets in the blood system (Fujimura et al. 2002). Physiological stress from acute bouts of exercise may also induce BDNF expression in immune system blood cells (Brunelli et al. 2012). In humans, transient elevations of serum BDNF levels have been found following acute and chronic exercise (Babaei et al. 2013; Ferris et al. 2007; Griffin et al. 2011; Håkansson et al. 2017; Leckie et al. 2014; Marquez et al. 2015; Rasmussen et al. 2009; Ruscheweyh et al. 2011; Schmolesky et al. 2013; Seifert et al. 2010; Szuhany et al. 2015; but compare Goda et al. 2013). Basal (resting) BDNF levels may also be increased slightly by chronic aerobic exercise in young adults (Szuhany et al. 2015; Zoladz et al. 2008) though this was not found in a five-week intervention by Griffin et al (2011) (see also Afzalpour 2015; Marquez et al. 2015). Crucially, exercise-associated improvements in spatial reasoning and memory do not occur in rats when a BDNF antagonist is administered (Vaynman et al. 2004). This strongly suggests BDNF is necessary for the production of cognitive benefits from exercise. A systematic review by 
Huang et al. (2014) examines in more detail the effects of acute and chronic exercise on BDNF specifically, indicating that aerobic but not strength/resistance training generally increases peripheral BDNF concentrations.

In addition to elevated BDNF levels, increased phosphorylation of cAMP response element-binding protein (CREB) and protein kinase $\mathrm{B}$ (PKB, also known as serine/threonine protein kinase or Akt) in the mouse hippocampus has been observed following 5 weeks of exercise (Aguiar et al. 2011; Chae and Kim 2009; Chen and RussoNeustadt 2005, 2009). CREB is known to have a role in synaptic plasticity, particularly in long-term potentiation (see Benito and Barco 2010 for review), and mouse studies have demonstrated that CREB is necessary for exercise-induced BDNF expression (Chen and Russo-Neustadt 2009; Conti et al. 2002). CREB is also necessary for the survival of new neurons in the hippocampus (Jagasia et al. 2009). PKB has many roles including cell growth and proliferation (see Brazil and Hemmings 2001 for review), and appears to reduce hippocampal apoptosis (Chae and Kim 2009).

Insulin-like growth factor-1 (IGF-1) also appears important. Exercise-induced neurogenesis in the rat hippocampus is inhibited following injection of a serum that blocks IGF-1 from leaving the bloodstream and entering the cerebrospinal fluid (Trejo et al. 2001). IGF-1 also contributes greatly to the exercise-induced effects of BDNF on recall (Ding, Vaynman et al. 2006). A critical role of IGF-1 delivery from the bloodstream for exercise-induced neurogenesis explains why increased cerebral circulation appears so important, as IGF-1 is a hormone that normally circulates throughout the bloodstream. Neuronal uptake of IGF-1 is stimulated by exercise, and these neurons then show signs of activity and increase their expression of BDNF (Carro et al. 2000).

Woods et al. (2012) describe how in the elderly, there is a well-documented chronic increase in baseline systemic inflammation, and they propose that this is at least partially 
caused by immunosenescence. Systemic inflammation contributes to CNS inflammation (Perry, 2004), which reduces the efficacy of IGF-1 in promoting protein synthesis (Frost et al. 1997; Strle et al. 2004). Chronic aerobic exercise serves to reduce systemic inflammation via several mytokine and cytokine cascades (for review see Petersen and Pedersen 2005; Cotman et al. 2007, Mathur and Pederson 2008). Woods et al. (2012) observe that aerobic exercise interventions lasting at least 6 months have been found to reduce biomarkers of inflammation that contribute to this inhibition of IGF-1 signalling (e.g. Kadoglou et al. 2007; Kohut et al. 2006; Mattusch et al. 2000; Nicklas et al. 2009; Vieira et al. 2009; cf. Hammett et al. 2004). According to the review by Woods et al. (2012), the mechanisms by which aerobic exercise reduces inflammation are primarily driven by fat loss (as adipose tissue is known to release pro-inflammatory factors). In addition, they propose that independent of fat loss, exercise stimulates muscle production of anti-inflammatory factors, and also stimulates the vagus nerve, causing peripheral antiinflammatory effects. Woods et al. (2012) thus offer that the anti-inflammatory effects of chronic exercise can serve to restore IGF-1 signalling which, as discussed above, contributes to BDNF expression and neurogenesis - particularly when neuronal IGF-1 uptake is elevated following acute bouts of aerobic exercise (Carro et al. 2000).

It has also been shown that serotonin (5-HT) is necessary for exercise-induced hippocampal neurogenesis, but not for unrelated baseline neurogenesis - which has implications for disorders involving serotonin deficiency (Klempin et al. 2013). Vascular endothelial growth factor (VEGF) also appears necessary only for exercise-induced hippocampal neurogenesis (Fabel et al. 2003), and regulates CXCL12 (Salcedo et al. 1999), which further indicates the importance of endothelial cell proliferation and angiogenesis in exercise-induced cognitive benefits. In mice, exercise induces expression of VEGF in the hippocampus (Morland et al. 2017; Tang et al. 2010) as well as the lungs and locomotor skeletal muscles, though increased expression is exclusive to the hippocampus in hypoxic conditions (Tang et al. 2010). In humans, exercise at high altitudes has been observed to increase serum VEGF levels immediately after exercise, 
with elevated levels lasting up to one month after training (Asano et al. 1998; Schobersberger et al. 2000). Finally, exercise appears to increase the permeability of the human blood-brain barrier (BBB) (Bailey et al. 2011), which could also contribute to the aforementioned effects. A review by Voss et al. (2013) offers further insight into human and animal studies on upregulation of neurotrophic factors and consequent synaptic plasticity via exercise, as well as genetic considerations. Overall, we suggest that vascular adaptation from chronic fitness improvements serves to enhance the beneficial neurocognitive effects from transient elevations of these neurotrophins during and after acute exercise bouts.

\section{Neurogenesis, Plasticity, and Learning}

Aerobic exercise has been shown to increase neurogenesis in the rat and mouse dentate gyrus (Nokia et al. 2016; Marlatt et al. 2012; van Praag et al. 1999) and the rat hypothalamus (Niwa et al. 2016). Aerobic exercise also increases brain volume in older adults (Colcombe et al. 2006; Erickson et al. 2011). Cardiovascular fitness has been associated with sparing of age-related grey- and white- matter decline (Colcombe et al. 2003; Voss et al. 2016). BDNF has a key role in neurogenesis and supports neural stem cells through tropomyosin receptor kinase B (TrkB) activation (Bartkowska et al. 2007; Bath et al. 2012), and it also modulates synaptic efficacy (Vithlani et al. 2013), so it is reasonable to suggest that elevated BDNF (along with the other supporting neurotrophic factors discussed above) is involved in aerobic exercise-induced neurogenesis and neuroprotective effects.

Indeed, Palmer et al. (2000) demonstrated that adult neurogenesis in the subgranular zone of the hippocampal dentate gyrus (giving rise to excitatory granule cells) is concentrated in regions proximal to endothelial cells attached to the vasculature; an implication of this finding is that angiogenesis could promote neurogenesis by strengthening or expanding the cerebral vasculature, enhancing the neurogenic niche. In the subventricular zone of the lateral ventricles, another site of adult neurogenesis (Ming 
and Song, 2011), voluntary exercise stimulates neurogenesis (Chae et al. 2014) and attenuates the decrease in cell proliferation caused by corticosterone (a stress response hormone) in rats (Lee et al. 2016). In the rat dentate gyrus, exercise promotes synaptic plasticity via increased cellular proliferation and dendrite complexity, length, and spine density (Eadie et al. 2005). Restricting exercise in rats impairs neurogenesis and reduces BDNF and VEGF levels (Yasuhara et al. 2007). It has also been demonstrated that exercise can recover impaired neurogenesis levels in the mouse hippocampus, and that this recovery is associated with enhanced BDNF gene expression and performance in an object recognition task (Lafenêtre et al. 2010).

Yet promotion of neurogenesis and synaptic plasticity may not be sufficient to achieve optimal cognitive benefits from exercise as a large proportion of newborn neurons fail to integrate into hippocampal circuits and die after 1-2 weeks (Cameron and Mckay 2001; Curlik et al. 2014; Dayer et al. 2003; Gould et al. 1999). However, despite much speculation (see Vivar \& van Praag, 2013 for review), it appears that the long-term survivability of these granule cells is enhanced after hippocampus-dependent (or hippocampus-activating) learning during early phases of the cells' lifespan (DiFeo and Shors 2017; Gould et al. 1999; Sisti et al. 2007). This learning-enhanced survival correlates to task performance (Leuner et al. 2004) and contributes to spatial long-term memory (Snyder et al. 2005). New granule cells are more likely than existing granule cells to be integrated into spatial memory networks (Kee et al. 2007). The new granule cells also receive preferential input from the perirhinal and lateral entorhinal cortex, areas involved in visual discrimination, object recognition, and sensory information processing (Vivar et al. 2012; see Vivar and van Praag 2013 for review).

Therefore, we propose that although aerobic exercise can promote hippocampal neurogenesis through the mechanisms discussed above, subsequent learning in hippocampus-dependent domains such as spatial reasoning and memory is likely necessary for functional integration of new neurons and the manifestation of cognitive 
benefits. Practically, several studies have found that combining exercise interventions with cognitive training produces significant benefits compared to exercise or cognitive training alone (e.g. Barnes et al. 2013; Smith et al. 2013). In regions of the brain where neurogenesis is not known to occur, activation of task-dependent regions from cognitive training in other domains and consequent increased metabolic demand could result in proportionally greater oxygenation and neurotrophin delivery to those regions, enhancing plasticity. This seems likely to occur primarily in frontal regions susceptible to agerelated cognitive decline (Colcombe et al. 2003; Raz et al. 2004), where sparing effects of exercise and increased grey matter volume associated with enhanced performance on memory tasks have been observed (e.g. Colcombe et al. 2003; Colcombe et al. 2006; Gordon et al. 2008; Ruscheweyh et al. 2011). Long-term (6-12 months) aerobic fitness interventions have been associated with increased white matter volume and connectivity in the prefrontal cortex (Colcombe et al. 2006; Voss et al. 2010; Voss, Heo et al. 2013), and cardiovascular fitness is also associated with white matter volume in the corpus callosum (Johnson et al. 2012). It can be speculated that these regions are more malleable and thus more sensitive to exercise-induced neuroenhancement.

\section{From Exercise to Cognition: A Model}

It is important to avoid causal oversimplification and consider that exercise-induced cognitive benefits likely arise from the combined effects of multiple mechanisms. Based on the findings summarised in this review, and following the suggestion of Etnier et al. (2006) that cardiovascular fitness could be the first component in a cascade of mechanisms, we propose the model shown in Figure 1 for exercise-induced cognitive enhancement.

[Figure 1]

[Table 1] 
First, physical activity (primarily aerobic) improves cardiovascular fitness. This supports cerebral angiogenesis (Kleim et al. 2002; Swain et al. 2003) possibly through mechanical shear stress on blood vessel walls (Makanya et al. 2009), responses to exercise-induced hypoxemia (Patt et al. 1997), CXCL12 upregulation (Parachikova et al. 2008), and FOXO1/FOXO3a suppression (Slopack et al. 2014; Sanchez 2015). Aerobic exercise elevates serum and hippocampal VEGF (Asano et al. 1998; Morland et al. 2017; Schobersberger et al. 2000; Tang et al. 2010), and promotes EPCs and eNOS (Gertz et al. 2006), which support the maintenance of the vascular endothelium (Förstermann and Münzel 2006) and further contribute to angiogenesis (Gertz et al. 2006; Morland et al. 2017). Cerebral angiogenesis explains observed increases in cerebral circulation (Pereira et al. 2007) and cerebral oxygenation (Dupuy et al. 2015); in combination with transiently increased permeability of the BBB (Bailey et al. 2011) there will be more efficient bloodstream delivery of neurotrophins and supporting factors for brain plasticity during or following exercise. Exercise also reduces systemic inflammatory factors, which can restore inhibited IGF-1 signalling (e.g. Kadoglou et al. 2007; Kohut et al. 2006; Mattusch et al. 2000; Vieira et al. 2009). Exercise increases phosphorylation of CREB (Aguiar et al. 2011; Chen \& Russo-Neustadt 2009), and stimulates neuronal IGF-1 uptake (Carro et al. 2000). With more efficient bloodstream delivery and improved signalling efficacy, elevated levels of IGF-1 can reach more neurons, which then increase their (CREB-mediated) expression of BDNF (Carro et al. 2000; Chen and Russo-Neustadt 2010; Conti et al. 2002; Ding et al. 2006). The rise in CREB and BDNF after repeated acute bouts of exercise enhances neurogenesis (Bartkowska et al. 2007; Bath et al. 2012; Jagasia et al. 2009), and capacity for neural plasticity is increased in the hippocampus along with frontal and parietal regions of the brain (Colcombe et al. 2003; Eadie et al. 2005; Gordon et al. 2008; Marlatt et al. 2012; Voss et al. 2010) in a process that likely involves exercise-induced PKB and CREB phosphorylation (cf. Benito and Barco 2010; Brazil and Hemmings 2001; Chae and Kim 2009). The areas most susceptible to this plasticity are functionally associated with the cognitive domains that see the most exercise-induced benefits (Colcombe et al. 2003; Gordon et al. 2008), such as executive 
functions (e.g., Colcombe and Kramer 2003; Davis et al. 2011; Voss et al. 2010) and memory (e.g. Babaei et al. 2013; Håkansson et al. 2017; Holzschneider et al. 2012; Ruscheweyh et al. 2011; Snyder et al. 2005; Vaynman et al. 2004). Domain-specific learning concurrent with exercise interventions may enhance these benefits by promoting the survival of immature neurons less than four weeks old (cf. DiFeo and Shors 2017; Gould et al. 1999; Sisti et al. 2007; Snyder et al. 2005), however there is still sparse evidence regarding the optimal timing between exercise bouts and cognitive training.

In summary, angiogenesis is a relatively chronic adaptation from regularly repeated exercise (over several weeks or months), which enhances the transient effects of acute bouts of exercise such as elevated levels of neurotrophins and supporting factors by improving bloodstream delivery to critical brain areas. These factors enhance neurogenesis and brain plasticity, which yields cognitive benefits most effectively when combined with domain-specific training.

This model is certainly not complete, but based on the studies mentioned in this review, it could be considered a reasonable starting point and we hope it will be expanded on in the future as more specific pathways are elucidated and its predictions are further tested. For example, one prediction of this model is that if angiogenesis could somehow be inhibited, then we would not expect to see any significant cognitive benefits after several weeks of exercise as the key stage of improved cerebral circulation would not occur. It is important to note that this model only describes one of perhaps several potential pathways for exercise-induced cognitive benefits; others may involve higherintensity, shorter duration exercise (and high-intensity interval training), which has been studied less than aerobic exercise but appears to increase VEGF in rats (Flora et al. 2016) and serum BDNF in humans (Yarrow et al. 2010). Other methods of IGF-1 upregulation or promotion of angiogenesis might be incorporated into the model, and further research might account for non-linear interactions of the different stages, all of which could contribute individually to a range of eventual cognitive benefits. Furthermore we do not 
make any claim about a consensus for the timescales listed in Figure 1, but rather we suggest that the observed times for effects to appear in the cited studies (Table 1) indicate an approximate order of events that we expect will be supported by future studies.

Although cardiovascular fitness is important in the model we have presented here, it is likely not always necessary for other possible mechanisms of exercise-induced cognitive benefits. This could help explain the relatively rare but notable exceptions in an otherwise large body of supporting evidence. For example, Flöel et al. (2010) found that performance in a learning and memory task improved with physical activity, but this was not associated with cardiovascular fitness. Smiley-Oyen et al. (2008) also found executive functions improved with aerobic exercise, but not with changes in cardiovascular fitness. Resistance training has occasionally been shown to improve executive functions and memory despite small or non-significant changes in cardiovascular fitness (Nagamatsu et al. 2012; Weinberg et al. 2013) for young and old adults, and a meta-analysis by Smith et al. (2011) reported that the benefits of aerobic exercise on some (but not all) cognitive domains were increased when combined with anaerobic exercise. In addition to other variables such as environmental enrichment or the specific type, duration, frequency, and intensity of exercise, the emergence of cognitive benefits could also be affected by age. For some domains such as executive functions or memory, these benefits could be of a more neuroprotective nature in middle-aged adults such that objective improvements in cognition do not become apparent until old age (during natural cognitive decline) and are also more noticeable in children (during natural cognitive development). Exercise is cognitively beneficial at any age. Yet, cardiovascular fitness-related improvements tend to be most noticeable during childhood and old age as this is when the brain undergoes significant structural changes. Additionally, aerobic exercise contributes to the alleviation of cerebrovascular dysfunction, which is associated with age-related cognitive decline (Marshall and Lazar 2011). 
To further refine the model described by Figure 1 and further investigate the role of cardiovascular fitness in cognition, future studies can be strengthened by several methodological factors. These include a control group to guard against retesting effects; a control group to guard against any potential effect of environmental enrichment (e.g. a group that starts a new social or leisure activity not involving exercise); the use of a standardised neuropsychological battery to test other cognitive domains beyond executive functions; controls for possible effects of sample population characteristics such as socioeconomic status, intelligence quotient, mental well-being/stress, baseline fitness and prior physical activity levels; controls for possible effects of diet/nutrition; measures of baseline cortisol levels which could affect memory performance (e.g. Maass et al. 2015); the inclusion of multiple age groups; multiple assessments of cardiovascular fitness (e.g., $\mathrm{VO}_{2} \mathrm{max}, \mathrm{VO}_{2}$ peak, $\mathrm{CBV}$, and lactate threshold, to test for any difference between the measures); testing for gender differences, as the Colcombe and Kramer (2003) metaanalysis found that cognitive benefits were slightly greater for females than males and a meta-analysis by Szuhany et al (2015) suggests exercise-induced BDNF upregulation may be slightly greater for males; incorporating multiple exercise types (anaerobic and aerobic); varying exercise intensities and intervention durations to assess dose-response relationships as suggested by Etnier et al. (2006); and making use of increasingly accessible methods for analysing brain activity and oxygenation such as near-infrared spectroscopy (e.g. as used by Fabiani et al. 2014). Genetic influences should also be considered; for example, Erickson et al. (2013) found that carriers of a specific BDNF gene polymorphism perform poorly on a working memory assessment compared to noncarriers, but this impairment was offset by physical activity. See Denham et al. (2014) for a general review of exercise-related epigenetic modifications.

\section{Summary}

The mechanism by which physical activity results in cognitive benefits is complicated and it is likely that multiple pathways exist. Improvement in cardiovascular fitness is not strictly necessary in this process - it could indeed be bypassed in other pathways (e.g. 
those involving anaerobic exercise). But contemporary literature seems to support the idea that greater cardiovascular fitness can contribute to many improvements in cognition via multiple mechanisms that share in common upregulation of neurotrophins including BDNF, made more available by long-term improvements of cerebral circulation, yielding greater neurogenesis and improved capacity for adaptive brain plasticity. Future research will reveal more on how specific stages in this pathway arise and may be altered (e.g., by changing exercise parameters, the influence of external factors such as diet, and integrating different forms of cognitive training). Despite the remaining questions about the precise mechanisms involved, improving cardiovascular fitness emerges as even more appealing to those wishing for greater overall health - both physical and mental.

\section{Acknowledgement}

We would like to thank Fadi Ifram for preparing the Glossary.

\section{References}

Afzalpour ME, Chadorneshin HT, Foadoddini M, \& Eivari HA (2015) Comparing interval and continuous exercise training regiments on neurotrophic factors in rat brain. Physiol. Behav. 147:78-83.

Aguiar AS Jr, Speck AE, Prediger RD, Kapczinski F, \& Pinho RA (2008) Downhill training upregulates mice hippocampal and striatal brain-derived neurotrophic factor levels. J. Neural. Transm. 115:1251-1255.

Aguiar AS Jr, Castro AA, Moreira EL, Glaser V, Santos ARS et al (2011) Short bouts of mild-intensity physical exercise improve spatial learning and memory in aging rats: involvement of hippocampal plasticity via AKT, CREB and BDNF signaling. Mech. Ageing Dev. 132:560-567. 
Asano M, Kaneoka K, Nomura T, Asano K, Sone H et al (1998) Increase in serum vascular endothelial growth factor levels during altitude training. Acta Physiol. Scand. 162(4):455-460.

Babaei P, Azali AK, Soltani TB, \& Damirchi A (2013) Effect of six weeks of endurance exercise and following detraining on serum brain derived neurotrophic factor and memory performance in middle aged males with metabolic syndrome. J. Sports Med. Phys. Fitness 53(4):437-443.

Bailey DM, Evans KA, McEneny J, Young IS, Hullin DA et al (2011) Exercise-induced oxidative-nitrosative stress is associated with impaired dynamic cerebral autoregulation and blood-brain barrier leakage. Exp. Physiol. 96:1196-1207.

Barnes DE, Yaffe K, Satariano WA, \& Tager IB (2003) A longitudinal study of cardiorespiratory fitness and cognitive function in healthy older adults. J. Am. Geriatr. Soc. 51(4):459-465.

Barnes DE, Santos-Modesitt W, Poelke G, Kramer AF, Castro C et al (2013). The Mental Activity and eXercise (MAX) trial: a randomized controlled trial to enhance cognitive function in older adults. JAMA Intern. Med. 173(9):797-804.

doi:10.1001/jamainternmed.2013.189

Bartkowska K, Paquin A, Gauthier AS, Kaplan DR, \& Miller FD (2007) Trk signaling regulates neural precursor cell proliferation and differentiation during cortical development. Development 134:4369-4380.

Bath KG, Akins MR, \& Lee FS (2012) BDNF control of adult SVZ neurogenesis. Dev. Psychobiol. 54:578-589. 
Bekinschtein P, Cammarota M, Katche C, Slipczuk L, Rossato J et al (2008) BDNF is essential to promote persistence of long-term memory storage. Proc. Natl. Acad. Sci. U. S. A. 105:2711-2716.

Benito E, \& Barco A (2010) CREB's control of intrinsic and synaptic plasticity: implications for CREB-dependent memory models. Trend Neurosci. 33:230-240.

Berchtold NC, Chinn G, Cou M, Kesslak JP, \& Cotman CW (2005) Exercise primes a molecular memory for brain-derived neurotrophic factor protein induction in the rat hippocampus. Neurosci. 133:853-861.

Best, JR Nagamatsu LS, \& Liu-Ambrose T (2014). Improvements to executive function during exercise training predict maintenance of physical activity over the following year. Front. Hum. Neurosci. 8:353. doi:10.3389/fnhum.2014.00353

Black JE, Isaacs KR, Anderson BJ, Alcantara AA, \& Greenough WT (1990) Learning causes synaptogenesis, whereas motor activity causes angiogenesis, in cerebellar cortex of adult rats. Proc. Natl. Acad. Sci. U. S. A. 87:5568-72.

Brazil DP \& Hemmings BA (2001) Ten years of protein kinase B signaling: a hard Akt to follow. Trend Biochem. Sci. 11:657-664.

Brown AD, McMorris CA, Longman RS, Leigh R, Hill MD et al (2010) Effects of cardiorespiratory fitness and cerebral blood flow on cognitive outcomes in older women. Neurobiol. Aging 31(12):2047-2057. doi:10.1016/j.neurobiolaging.2008.11.002

Brunelli A, Dimauro I, Sgrò P, Emerenziani GP, Magi F, \& Baldari C (2012) Acute exercise modulates BDNF and pro-BDNF protein content in immune cells. Med. Sci. Sports Exerc. 44:1871-80. doi:10.1249/MSS.0b013e31825ab69b 
Cameron HA, \& Mckay RD (2001) Adult neurogenesis produces a large pool of new granule cells in the dentate gyrus. J. Comp. Neurol. 435:406-17.

Carro E, Nuñez A, Busiguina S, \& Torres-Aleman I (2000) Circulating insulin-like growth factor I mediates effects of exercise on the brain. J. Neurosci. 20:2926-2933.

Chae CH, Jung SL, An SH, Park BY, Kim TW et al (2014) Swimming exercise stimulates neuro-genesis in the subventricular zone via increase in synapsin I and nerve growth factor levels. Biol. Sport 31:309-314.

Chae CH, \& Kim HT (2009) Forced, moderate-intensity treadmill exercise suppresses apoptosis by increasing the level of NGF and stimulating phosphatidylinositol 3-kinase signaling in the hippocampus of induced aging rats. Neurochem. Int. 55:208-213.

Chang YK, Labban JD, Gapin JI, \& Etnier JL (2012). The effects of acute exercise on cognitive performance: a meta-analysis. Brain Res. 1453(250):87-101. doi:10.1016/j.brainres.2012.02.068

Chen MJ, \& Russo-Neustadt, AA (2005) Exercise activates the phosphatidylinositol 3kinase pathway. Mol. Brain. Res. 135:181-193.

Chen MJ \& Russo-Neustadt, AA (2009) Running exercise-induced up-regulation of hippocampal brain-derived neurotrophic factor is CREB-dependent. Hippocampus 19:962-972.

Colcombe SJ \& Kramer AF (2003) Fitness effects on the cognitive function of older adults: A meta-analytic study. Psychol. Sci. 14:125-130. 
Colcombe SJ, Erickson KI, Raz N, Webb AG, Cohen NJ et al (2003) Aerobic fitness reduces brain tissue loss in aging humans. J. Gerontol. A. Biol. Sci. Med. Sci. 58:176180.

Colcombe SJ, Kramer AF, Erickson KI, Scalf P, McAuley E et al (2004) Cardiovascular fitness, cortical plasticity, and aging. Proc. Natl. Acad. Sci. U.S.A. 101:3316-3321. doi:10.1073/pnas.0400266101

Colcombe SJ, Erickson KI, Scalf PE, Kim JS, Prakash RS et al (2006) Aerobic exercise training increases brain volume in ageing humans. J. Gerontol. 61 A:1166-1170.

Conti AC, Cryan JF, Dalvi A, Lucki I, \& Blendy JA (2002) cAMP response elementbinding protein is essential for the upregulation of brain-derived neurotrophic factor transcription, but not the behavioral or endocrine responses to antidepressant drugs. J. Neurosci. 22:3262-3268.

Cotman CW, Berchtold NC, \& Christie LA (2007) Exercise builds brain health: key roles of growth factor cascades and inflammation. Trends Neurosci. 30(9):464-72.

Curlik DM, DiFeo G, \& Shors TJ (2014) Preparing for adulthood: thousands upon thousands of new cells are born in the hippocampus during puberty, and most survive with effortful learning. Front. Neurosci. 8:70. doi:10.3389/fnins.2014.00070

Davis CL, Tomporowski PD, McDowell JE, Austin BP, Miller PH et al (2011) Exercise improves executive function and achievement and alters brain activation in overweight children: A randomized, controlled trial. Health Psychol. 30:91-98.

doi:10.1037/a0021766 
Dayer AG, Ford AA, Cleaver KM, Yassaee M, \& Cameron HA (2003). Short- term and long- term survival of new neurons in the rat dentate gyrus. J. Comp. Neurol. 460:56372.

Denham J, Marques FZ, O'Brien BJ, \& Charchar FJ (2014) Exercise: Putting action into our genome. Sports Med. 44:189.

DiFeo G \& Shors TJ (2017) Mental and physical skill training increases neurogenesis via cell survival in the adolescent hippocampus. Brain Res. 1654:95-101.

Ding Q, Vaynman S, Akhavan M, Ying Z, \& Gomez-Pinilla F (2006) Insulin-like growth factor I interfaces with brain-derived neurotrophic factor-mediated synaptic plasticity to modulate aspects of exercise-induced cognitive function. Neuroscience 140:823-833.

Ding Y-H, Li J, Zhou Y, Rafols JA, Clark JC, \& Ding Y (2006) Cerebral angiogenesis and expression of angiogenic factors in aging rats after exercise. Curr. Neurovascular Res. 3:15-23.

Dupuy O, Gauthier CJ, Fraser SA, Desjardins-Crèpeau L, Desjardins M et al (2015) Higher levels of cardiovascular fitness are associated with better executive function and prefrontal oxygenation in younger and older women. Front. Hum. Neurosci. 9:66. doi:10.3389/fnhum.2015.00066

Dustman RE, Ruhling RO, Russell EM, Shearer DE, Bonekat HW et al (1984) Aerobic exercise training and improved neuropsychological function of older individuals. Neurobiol. Aging 5:35-42. doi:10.1016/0197-4580(84)90083-6 
Eadie BD, Redila VA, \& Christie BR (2005) Voluntary exercise alters the cytoarchitecture of the adult dentate gyrus by increasing cellular proliferation, dendritic complexity, and spine density. J. Comp. Neurol. 486:39-47.

Ekstrand J, Hellsten J, \& Tingstöm A (2008) Environmental enrichment, exercise and corticosterone affect endothelial cell proliferation in adult rat hippocampus and prefrontal cortex. Neurosci. Letters 442:203-207.

Erickson KI, Voss MW, Prakash RS, Basak C, Szabo A et al (2011) Exercise training increases size of hippocampus and improves memory. Proc. Natl. Acad. Sci. U. S. A. 108:3017-3022. doi:10.1073/pnas.1015950108

Erickson KI, Banducci SE, Weinstein AM, MacDonald AW III, Ferrel RE et al (2013) The brain-derived neurotrophic factor Val66Met polymorphism moderates an effect of physical activity on working memory performance. Psychol. Sci. 24:1770-1779.

Etnier, JL, Nowell PM, Landers DM, \& Sibley BA (2006) A meta-regression to examine the relationship between aerobic fitness and cognitive performance. Brain Res. Rev. 52:119-130.

Fabel K, Fabel K, Tam B, Kaufer D, Baiker A et al (2003) VEGF is necessary for exercise-induced adult hippocampal neurogenesis. Eur. J. Neurosci. 18:2803-2812.

Fabiani M, Gordon BA, Maclin EL, Pearson MA, Brumback-Peltz CR et al (2014) Neurovascular coupling in normal aging: a combined optical, ERP and fMRI study. Neuroimage. 85:592-607. doi:10.1016/j.neuroimage.2013.04.113 
Ferris LT, Williams JS, \& Shen CL (2007) The effect of acute exercise on serum brainderived neurotrophic factor levels and cognitive function. Med. Sci. Sports Exerc. 39:728-734.

Flora R, Zulkarnain M, Sorena E, Dewa Gde Sathya Deva I, \& Widowati W (2016) Correlation between hypoxia inducible factor-1 $\alpha$ and vesicular endothelial growth factor in male Wistar rat brain tissue after anaerobic exercise. Trend Med. Res. 11:35-41. doi:10.3923/tmr.2016.35.41

Förstermann U, \& Münzel T (2006) Endothelial nitric oxide synthase in vascular disease: from marvel to menace. Circulation. 113:1708-1714.

Frost RA, Lang CH, \& Gelato MC (1997) Transient exposure of human myoblasts to tumor necrosis factor- $\alpha$ inhibits serum and insulin-like growth factor-I stimulated protein synthesis. Endocrinology 138(10):4153-9.

Fujimura H, Altar CA, Chen R, Nakamura T, Nakahashi T et al (2002) Brain-derived neurotrophic factor is stored in human platelets and released by agonist stimulation. Thromb. Haemostasis 87:728-734. doi:10.1016/j.bbi.2008.05.010

Fukai T, Siegfried MR, Ushio-Fukai M, Cheng Y, Kojda G, \& Harrison DG (2000) Regulation of the vascular extracellular superoxide dismutase by nitric oxide and exercise training. J. Clin. Invest. 105:1631-1639.

Gertz K, Priller J, Kronenberg G, Fink KB, Winter B et al (2006) Physical activity improves long-term stroke outcome via endothelial nitric oxide synthase-dependent augmentation of neovascularization and cerebral blood flow. Circ. Res. 99:1132-1140. 
Goda A, Ohgi S, Kinpara K, Shigemori K, Fukuda K, Schneider EB (2013) Changes in serum BDNF levels associated with moderate-intensity exercise in healthy young Japanese men. SpringerPlus 2:678. doi:10.1186/2193-1801-2-678

Gómez-Pinilla F, Ying Z, Roy RR, Molteni R, \& Reggie Edgerton V (2002) Voluntary exercise induces a BDNF-mediated mechanism that promotes neuroplasticity. J. Neurophysiol. 88:2187-2195.

Gordon BA, Rykhlevskaia EI, Brumback CR, Lee Y, Elavsky S et al (2008) Neuroanatomical correlates of ageing, cardiopulmonary fitness level, and education. Psychophysiology 45:825-838. doi:10.1111/j.1469-8986.2008.00676.x

Gould E, Beylin A, Tanapat P, Reeves A, Shors TJ (1999) Learning enhances adult neurogenesis in the hippocampal formation. Nat. Neurosci. 2:260-265. doi:10.1038/6365

Håkansson K, Ledreux A, Daffner K, Terjestam Y, Bergman P et al (2017) BDNF responses in healthy older persons to 35 minutes of physical exercise, cognitive training, and mindfulness: Associations with working memory function. J. Alzheimers Dis. 55:645-657. doi:10.3233/JAD-160593

Hammett CJ, Oxenham HC, Baldi JC, Doughty RN, Ameratunga R et al. (2004) Effect of six months' exercise training on C-reactive protein levels in healthy elderly subjects. J. Am. Coll. Cardiol. 44(12):2411-2413.

Hartmann M, Heumann R, \& Lessmann V (2001) Synaptic secretion of BDNF after highfrequency stimulation of glutamatergic synapses. The EMBO journal 20:5887-5897.

Hill RD, Storandt M, \& Malley M (1993) The impact of long-term exercise training on psychological function in older adults. J. Gerontol. 48:12-17. 
Hillman CH, Erickson KI, \& Kramer AF (2008) Be smart, exercise your heart: exercise effects on brain and cognition. Nat. Rev. Neurosci. 9:58-65.

Holzschneider K, Wolbers T, Röder B, \& Hötting K (2012) Cardiovascular fitness modulates brain activation associated with spatial learning. Neuroimage 59:3003-3014.

Huang EJ, \& Reichardt LF (2001) Neurotrophins: roles in neuronal development and function. Ann. Rev. Neurosci. 24:677-736.

Hyodo, K, Dan I, Kyutoku Y, Suwabe K, Byun K et al (2015) The association between aerobic fitness and cognitive function in older men mediated by frontal lateralization. NeuroImage 125:291-300. http://doi.org/10.1016/j.neuroimage.2015.09.062

Isaacs KR, Anderson BJ, Alcantara AA, Black JE, \& Greenough WT (1992) Exercise and the brain: angiogenesis in the adult rat cerebellum after vigorous physical activity and motor skill learning. J. Cereb. Blood Flow Metab. 12(1):110-119.

Jagasia R, Steib K, Englberger E, Herold S, Faus-Kessler T et al (2009) GABA-cAMP Response Element-Binding Protein Signaling Regulates Maturation and Survival of Newly Generated Neurons in the Adult Hippocampus. J. Neurosci. 29:7966-7977. doi:10.1523/JNEUROSCI.1054-09.2009

Johnson RA, Rhodes JS, Jeffrey SL, Garland T, Mitchell GS (2003) Hippocampal brainderived neurotrophic factor but not neurotrophin-3 increases more in mice selected for increased voluntary wheel running. Neuroscience 121:1-7. 
Johnson NF, Kim C, Clasey JL, Bailey A, \& Gold BT (2012) Cardiorespiratory fitness is positively correlated with cerebral white matter integrity in healthy seniors. Neuroimage 59:1514-23. doi:10.101/neuroimage.2011.08.032

Kadoglou NP, Iliadis F, Angelopoulou N, Perrea D, Ampatzidis G, et al. (2007) The antiinflammatory effects of exercise training in patients with type 2 diabetes mellitus. Eur. J. of Cardiovasc. Prev. Rehabil. 14(6):837-43.

Kawagoe T, Onoda K, \& Yamaguchi S (2017) Associations among executive function, cardiorespiratory fitness, and brain network properties in older adults. Sci. Rep. 7:40107. http://doi.org/10.1038/srep40107

Kee N, Teixeira CM, Wang AH, \& Frankland PW (2007) Preferential incorporation of adult-generated granule cells into spatial memory networks in the dentate gyrus. Nat. Neurosci. 10:355-362.

Kleim JA, Cooper NR, \& VandenBerg PM (2002) Exercise induces angiogenesis but does not alter movement representations within rat motor cortex. Brain Res. 934:1-6.

Klempin F, Beis D, Mosienko V, Kempermann G, Bader M, \& Alenina N (2013) Serotonin is required for exercise-induced adult hippocampal neurogenesis. J. Neurosci. 33:8270-8275.

Kohut ML, McCann DA, Russell DW, Konopka DN, Cunnick JE, et al. (2006) Aerobic exercise, but not flexibility/resistance exercise, reduces serum IL-18, CRP, and IL-6 independent of $\beta$-blockers, BMI, and psychosocial factors in older adults. Brain Behav. Immun. 20(3):201-9. 
Kojima M, Takei N, Numakawa T, Ishikawa Y, Suzuki S et al (2001) Biological characterization and optical imaging of brain-derived neurotrophic factor-green fluorescent protein suggest an activity-dependent local release of brain-derived neurotrophic factor in neuritis of cultured hippocampal neurons. J. Neurosci. Res. 64:110.

Kramer AF, Hahn S, Cohen NJ, Banich MT, McAuley E et al (1999) Ageing, fitness and neurocognitive function. Nature 400:418-419.

Lafenêtre P, Leske O, Ma-Högemeie Z, Haghikia A, Bichler Z et al (2010) Exercise can rescue recognition memory impairment in a model with reduced adult hippocampal neurogenesis. Front. Behav. Neurosci. 3:34. doi:10.3389/neuro.08.034.2009

Leßmann V, \& Brigadski T (2009) Mechanisms, locations, and kinetics of synaptic BDNF secretion: an update. Neurosci. Res. 65:11-22.

Leckie RL, Oberlin LE, Voss MW, Prakash RS, Szabo-Reed A, et al (2014) BDNF mediates improvements in executive function following a 1-year exercise intervention. Front. Hum. Neurosci. 8:985. doi:10.3389/fnhum.2014.00985

Lee T MC, Wong ML, Lau BW-M, Lee JC-D, Yau S-Y, \& So K-F (2014) Aerobic exercise interacts with neurotrophic factors to predict cognitive functioning in adolescents. Psychoneuroendocrino. 39:214-24. doi:10.1016/j.psyneuen.2013.09.019

Lee JC-D, Yau S-Y, Lee T MC, Lau BW-M, \& So K-F (2016) Voluntary wheel running reverses the decrease in subventricular zone neurogenesis caused by corticosterone. Cell Transplantation 25:1979-1986. doi:10.3727/096368916X692195 
Leuner B, Mendolia-Loffredo S, Kozorovitskiy Y, Samburg D, Gould E, \& Shors TJ (2004) Learning enhances the survival of new neurons beyond the time when the hippocampus is required for memory. J. Neurosci. 24:7477-7481.

Maass A, Duzel S, Goerke M, Becke A, Sobieray U et al (2015) Vascular hippocampal plasticity after aerobic exercise in older adults. Mol. Psychiatry 20:585-593. doi:10.1038/mp.2014.114

Maia AC Jr, Malheiros SM, da Rocha AJ, da Silva CJ, Gabbai AA et al (2005) $M R$ cerebral blood volume maps correlated with vascular endothelial growth factor expression and tumor grade in nonenhancing gliomas. Am. J. Neuroradiol. 26:777-783.

Makanya AN, Hlushchuk R, Djonov VG (2009) Intussusceptive angiogenesis and its role in vascular morphogenesis, patterning, and remodeling. Angiogenesis 12:113-123.

Marlatt MW, Potter MC, Lucassen PJ, \& van Praag H. (2012) Running throughout middle-age improves memory function, hippocampal neurogenesis, and BDNF levels in female C57BL/6J mice. Dev. Neurobiol. 72(6):943-952. doi:10.1002/dneu.22009

Marquez CMS, Vanaudenaerde B, Troosters T, \& Wenderoth N (2015) High-intensity interval training evokes larger serum BDNF levels compared with intense continuous exercise. J. Appl. Psychol. 119:1363-73.

Marshall RS, \& Lazar RM (2011) Pumps, aqueducts, and drought management: vascular physiology in vascular cognitive impairment. Stroke 42:221-226.

Mathur N \& Pedersen BK (2008) Exercise as a mean to control low-grade systemic inflammation. Mediat. Inflamm 2008. 
Mattusch F, Dufaux B, Heine O, Mertens I, \& Rost R (2000) Reduction of the plasma concentration of C-reactive protein following nine months of endurance training. Intl. J. Sports Med. 21(01):21-4.

Ming GL, \& Song H (2011). Adult neurogenesis in the mammalian brain: significant answers and significant questions. Neuron 70:687-702.

Morland C, Andersson KA, Haugen ØР, Hadzic A, Kleppa L, et al (2017) Exercise induces cerebral VEGF and angiogenesis via the lactate receptor HCARI. Nature Commun. 8.

Nagamatsu LS, Handy TC, Hsu CL, Voss M, \& Liu-Ambrose T (2012) Resistance training promotes cognitive and functional brain plasticity in seniors with probable mild cognitive impairment. Arch. Intern. Med. 172(8):666-668.

Neeper SA, Gómez-Pinilla F, Choi J, \& Cotman C (1995) Exercise and brain neurotrophins. Nature 373:109.

Nicklas BJ \& Brinkley TE (2009) Exercise training as a treatment for chronic inflammation in the elderly. Exerc. Sports Sci. Rev. 37(4):165.

Nokia MS, Lensu S, Ahtiainen JP, Johansson PP, Koch LG et al (2016) Physical exercise increases adult hippocampal neurogenesis in male rats provided it is aerobic and sustained. J. Physiol. 594(7):1855-73. doi:10.1113/JP271552

Niwa A, Nishibori M, Hamasaki S, Kobori T, Liu K et al (2016) Voluntary exercise induces neurogenesis in the hypothalamus and ependymal lining of the third ventricle. Brain Struct. Func. 221(3):1653-1666. 
Palmer TD, Willhoite AR, \& Gage FH (2000) Vascular niche for adult hippocampal neurogenesis. J. Comp. Neurol. 425:479-494.

Parachikova A, Nichol KE, \& Cotman CW (2008) Short-term exercise in aged Tg2576 mice alters neuroinflammation and improves cognition. Neurobiol. Dis. 30:121-129. doi:10.1016/j.nbd.2007.12.008

Patt S, Sampaolo S, Théallier-Jankó A, Tschairkin I, \& Cervós-Navarro J (1997) Cerebral angiogenesis triggered by severe chronic hypoxia displays regional differences. J. Cereb. Blood Flow Metab. 17:801-806.

Pereira, AC, Huddleston DE, Brickman AM, Sosunov AA, Hen R, et al (2007) An in vivo correlate of exercise-induced neurogenesis in the adult dentate gyrus. Proc. Natl. Acad. Sci. U. S. A. 104:5638-5643. doi:10.1073/pnas.0611721104

Perry VH (2004) The influence of systemic inflammation on inflammation in the brain: implications for chronic neurodegenerative disease. Brain Behav. Immun. 18(5):407-13.

Petersen AM \& Pedersen BK (2005) The anti-inflammatory effect of exercise. J. Appl. Physiol. 98(4):1154-62.

Predovan D, Fraser SA, Renaud M, \& Bherer L (2012) The effect of three months of aerobic training on stroop performance in older adults. J. Ageing Res. vol. 2012, Article ID 269815, 7 pages. doi:10.1155/2012/269815

Rasmussen P, Brassard P, Adser H, Pedersen MV, Leick L, Hart E et al (2009) Evidence for a release of brain-derived neurotrophic factor from the brain during exercise. Exp. Physiol. 94:1062-1069. doi:10.1113/expphysiol.2009.048512. 
Raz N, Gunning-Dixon F, Head D, Rodrigue KM, Williamson A, \& Acker JD (2004) Aging, sexual dimorphism, and hemispheric asymmetry of the cerebral cortex: replicability of regional differences in volume. Neurobiol. Aging 25:377-96.

Ruscheweyh R, Willemer C, Krüger K, Duning T, Warnecke T et al (2011) Physical activity and memory functions: an interventional study. Neurobiol. Aging, 32:1304-19. doi:10.1016/j.neurobiolaging.2009.08.001

Salcedo R, Wasserman K, Young HA, Grimm MC, Howard OM et al (1999) Vascular endothelial growth factor and basic fibroblast growth factor induce expression of CXCR4 on human endothelial cells: In vivo neovascularization induced by stromal-derived factor-1alpha. Am. J. Pathol. 154:1125-1135.

Sanchez AM (2015) FoxO transcription factors and endurance training: a role for FoxO1 and FoxO3 in exercise- induced angiogenesis. J. Physiol. 593(2):363-364.

Schobersberger W, Hobisch-Hagen P, Fries D, Wiedermann F, \& Rieder-Scharinger J, (2000). Increase in immune activation, vascular endothelial growth factor and erythropoietin after an ultramarathon run at moderate altitude. Immunobiol. 201(5):611620.

Schmolesky MT, Webb DL, \& Hansen RA (2013) The effects of aerobic exercise intensity and duration on levels of brain-derived neurotrophic factor in healthy men. $\mathrm{J}$. Sports. Sci. Med. 12:502-511.

Seifert T, Brassard P, Wissenberg M, Rasmussen P, Nordby P et al (2010) Endurance training enhances BDNF release from the human brain. Am. J. Physiol. Regul. Integr. Comp. Physiol. 298:R372-R377. doi:10.1152/ajpregu.00525.2009 
Sisti HM, Glass AL, \& Shors TJ (2007) Neurogenesis and the spacing effect: learning over time enhances memory and the survival of new neurons. Learn. Mem.14:368-375.

Slopack D, Roudier E, Liu ST, Nwadozi E, Birot O, \& Haas TL (2014) Forkhead BoxO transcription factors restrain exercise- induced angiogenesis. J. Physiol. 592(18):406982.

Smith PJ, Blumenthal JA, Hoffman BM, Strauman TA, Welsh-bohmer K, et al (2011) Aerobic exercise and neurocognitive performance: a meta- analytic review of randomized controlled trials. Psychosom. Med. 72(3):239-252. doi:10.1097/PSY.0b013e3181d14633.Aerobic

Smith AM, Spiegler KM, Sauce B, Wass CD, Sturzoiu T, \& Matzel LD (2013) Voluntary aerobic exercise increases the cognitive enhancing effects of working memory training. Behav. Brain Res. 256:626-635. doi:10.1016/j.bbr.2013.09.012

Strle K, Broussard SR, McCusker RH, Shen WH, Johnson RW et al. (2004) Proinflammatory cytokine impairment of insulin-like growth factor I-induced protein synthesis in skeletal muscle myoblasts requires ceramide. Endocrinology 145(10):4592602.

Struthers CW, van Monsjou E, Ayoub M, \& Guilfoyle JR (2017) Fit to forgive: Effect of mode of exercise on capacity to override grudges and forgiveness. Front. Psychol. 8:110. doi:10.3389/fpsyg.2017.00538

Snyder JS, Hong NS, McDonald RJ, \& Wojtowicz JM (2005) A role for adult neurogenesis in spatial long-term memory. Neuroscience 130:843-852. 
Smiley-Oyen AL, Lowry KA, Francois SJ, Kohut ML, \& Ekkekakis P (2008) Exercise, fitness, and neurocognitive function in older adults: The 'selective improvement' and 'cardiovascular fitness' hypotheses. Ann. Behav. Med. 36:280-291.

Soya H, Nakamura T, Deocaris CC, Kimpara A, Iimura M et al (2007) BDNF induction with mild exercise in the rat hippocampus. Biochem. Bioph. Res. Co. 358:961-967.

Swain RA, Harris AB, Wiener EC, Dutka MV, Morris HD, Theien BE et al (2003) Prolonged exercise induces angiogenesis and increases cerebral blood volume in primary motor cortex of the rat. Neuroscience 117:1037-1046.

Szuhany KL, Bugatti M, \& Otto MW (2015) A meta-analytic review of the effects of exercise on brain-derived neurotrophic factor. J. Psychiatr. Res. 60:56-64.

doi:10.1016/j.psychires.2014.10.003

Tang K, Xia FC, Wagner PD, \& Breen EC (2010) Exercise-induced VEGF transcriptional activation in brain, lung and skeletal muscle. Respir. Physiol. Neurobiol. 170(1):16-22.

Themanson JR, Hillman CH (2006) Cardiorespiratory fitness and acute aerobic exercise effects on neuroelectric and behavioral measures of action monitoring. Neuroscience 141:757-67.

Trejo JL, Carro E, Torres-Aleman I (2001) Circulating insulin-like growth factor I mediates exercise-induced increases in the number of new neurons in the adult hippocampus. J. Neurosci. 21:1628-1634. 
Van Praag H, Kempermann G, Gage FH (1999) Running increases cell proliferation and neurogenesis in the adult mouse dentate gyrus. Nat. Neurosci. 2:266-270.

doi:10.1038/6368

Vaynman S, Ying Z, \& Gómez-Pinilla F (2004) Hippocampal BDNF mediates the efficacy of exercise on synaptic plasticity and cognition. Eur. J. Neurosci. 20:2580-2590.

Vieira VJ, Hu L, Valentine RJ, McAuley E, Evans EM et al. (2009) Reduction in trunk fat predicts cardiovascular exercise training-related reductions in C-reactive protein. Brain Behav. Immun. 23(4):485-91.

Vithlani M, Hines RM, Zhong P, Terunuma M, Hines DJ, et al (2013) The ability of BDNF to modify neurogenesis and depressive-like behaviors is dependent upon phosphorylation of tyrosine residues $365 / 367$ in the $G A B A_{A}$-receptor $\gamma 2$ subunit. $\mathrm{J}$. Neurosci. 33:15567-15577. doi:10.1523/JNEUROSCI.1845-13.2013

Vivar C, Potter MC, Choi J, Lee J-Y, Stringer TP et al (2012) Monosynaptic inputs to new neurons in the dentate gyrus. Nat. Commun. 3:1107. doi:10.1038/ncomms2101

Vivar C, \& van Praag H (2013) Functional circuits of new neurons in the dentate gyrus. Front. Neural Circuits 7:15. doi:10.3389/fncir.2013.00015

Voelcker-Rehage C, Godde B, \& Staudinger UM (2010). Physical and motor fitness are both related to cognition in old age. Eur. J. Neurosci. 31(1):167-176. doi:10.1111/j.14609568.2009.07014.x

Voss MW, Prakash RS, Erickson KI, Basak C, Chaddock L et al (2010) Plasticity of brain networks in a randomized intervention trial of exercise training in older adults. Front. Aging Neurosci. 2:1-17. 
Voss MW, Vivar C, Kramer AF, \& van Praag H (2013) Bridging animal and human models of exercise-induced brain plasticity. Trend. Cogn Sci. 17(10): 525-544.

Voss MW, Heo S, Prakash RS, Erickson KI, Alves H et al (2013) The influence of aerobic fitness on cerebral white matter integrity and cognitive function in older adults: Results of a one-year exercise intervention. Hum. Brain Mapp. 34: 2972-2985. doi:10.1002/hbm.22119

Voss MW, Weng TB, Burzynska AZ, Wong CN, Cooke GE et al (2016) Fitness, but not physical activity, is related to functional integrity of brain networks associated with aging. NeuroImage, 131:113-125.

Weinberg L, Hasni A, Shinohara M, \& Duarte A (2014) A single bout of resistance exercise can enhance episodic memory performance. Acta Psychol. 153:13-9. http://doi.org/10.1016/j.actpsy.2014.06.011

Woods JA, Wilund KR, Martin SA, \& Kistler BM (2012) Exercise, inflammation and aging. Aging Dis. 3(1):130.

Yarrow JF, White LJ, McCoy SC, \& Borst SE (2010) Training augments resistance exercise induced elevation of circulating brain derived neurotrophic factor (BDNF). Neurosci. Lett. 479:161-165. doi:10.1016/j.neulet.2010.05.058

Yasuhara T, Hara K, Maki M, Matsukawa N, Fujino H et al (2007) Lack of exercise, via hindlimb suspension, impedes exogenous neurogenesis. Neurosci. 149:182-191.

Young J, Angevaren M, Rusted J, \& Tabet N (2015) Aerobic exercise to improve cognitive function in older people without known cognitive impairment. The Cochrane 
Database of Systematic Reviews, 4(4):CD005381.

doi:10.1002/14651858.CD005381.pub4

Zoladz JA, Pilc A, Majerczak J, Grandys M, Zapart-Bukowska J, \& Duda K (2008)

Endurance training increases plasma brain-derived neurotrophic factor concentration in young healthy men. J. Physiol. Pharmacol. 59:119-32. 


\section{Figure Legend}

Figure 1. A model for the effects of physical activity on cognition. Key stages are highlighted with their contributing factors listed underneath. Times for long-term effects to appear from regular repeated exercise in [brackets] are estimates taken from the longitudinal studies cited in this review and may vary with different methodologies. Short-term effects take place during or immediately after acute bouts of exercise; $\mathrm{BBB}=$ blood-brain barrier. $\mathrm{BDNF}=$ brain-derived neurotrophic factor. $\mathrm{CBV}=$ cerebral blood volume. $\mathrm{CREB}=\mathrm{cAMP}$ response element-binding protein. $\mathrm{CXCL} 12=\mathrm{C}-\mathrm{X}-\mathrm{C}$ motif chemokine $12 . \mathrm{DG}=$ dentate gyrus. $\mathrm{eNOS}=$ endothelial nitric oxide synthase. $\mathrm{EPC}=$ endothelial progenitor cells. FOXO1/FOXO3a = forkhead box proteins $\mathrm{O} 1$ and O3a. IGF$1=$ insulin-like growth factor $1 . \mathrm{PKB}=$ protein kinase $\mathrm{B} . \mathrm{VEGF}=$ vascular endothelial growth factor.

\section{Table Caption}

Table 1. Studies cited in this review that contribute to the outcomes included in Figure 1. Subject ages are given as a range, mean, or mean \pm SD as specified in each study. Times refer to the point at which outcomes were measured after the start of the exercise intervention, if applicable. "Time of Outcome" refers to the only time at which the outcome was measured (e.g. following sacrifice in animal studies); actual effects possibly occurred earlier. ${ }^{\dagger}$ Review article. $\mathrm{BBB}=$ blood-brain barrier. $\mathrm{BDNF}=$ brain-derived neurotrophic factor. $\mathrm{CBV}=$ cerebral blood volume. $\mathrm{CREB}=\mathrm{cAMP}$ response elementbinding protein. CXCL12 $=\mathrm{C}-\mathrm{X}-\mathrm{C}$ motif chemokine $12 . \mathrm{DG}=$ dentate gyrus. eNOS $=$ endothelial nitric oxide synthase. $\mathrm{EPC}=$ endothelial progenitor cells. $\mathrm{FOXO1/FOXO3a}=$ forkhead box proteins $\mathrm{O} 1$ and $\mathrm{O} 3 \mathrm{a}$. IGF-1 = insulin-like growth factor-1. $\mathrm{PKB}=$ protein kinase $\mathrm{B} . \mathrm{VEGF}=$ vascular endothelial growth factor. 


\section{Physical Activity}

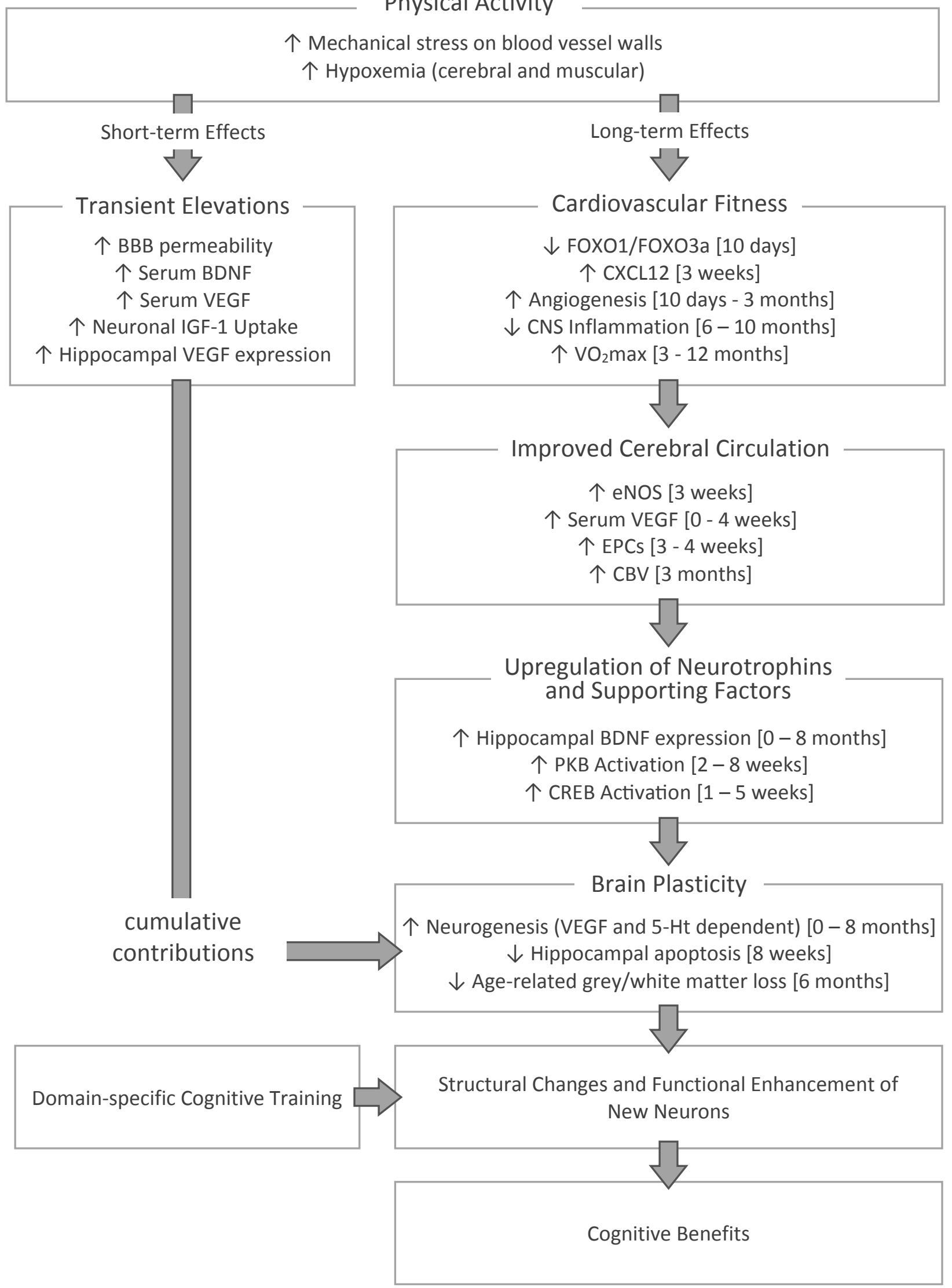




\begin{tabular}{|c|c|c|c|c|c|c|}
\hline Outcome & Reference & Species & Sex & $\begin{array}{l}\text { Sample } \\
\text { Size }\end{array}$ & Age of Subjects & $\begin{array}{l}\text { Time of Outcome } \\
\text { Measurement }\end{array}$ \\
\hline \multicolumn{7}{|l|}{ Physical Activity } \\
\hline $\begin{array}{l}\uparrow \text { Mechanical stress on blood vessel } \\
\text { walls }\end{array}$ & Makanya et al. 2009†† & $\mathrm{N} / \mathrm{A}$ & $\mathrm{N} / \mathrm{A}$ & $\mathrm{N} / \mathrm{A}$ & $\mathrm{N} / \mathrm{A}$ & N/A \\
\hline $\begin{array}{l}\uparrow \text { Hypoxemia [contributing to } \\
\text { angiogenesis] }\end{array}$ & Patt et al. 1997 & Rat & Male & 60 & 220 Days & 130 Days ${ }^{\dagger}$ \\
\hline \multicolumn{7}{|l|}{ Cardiovascular Fitness } \\
\hline$\downarrow$ FOXO1/FOXO3a & Slopack et al. 2014 & Mouse & Female & 13 & 9 Weeks & 10 Days \\
\hline 个 CXCL12 & Parachikova et al. 2008 & Mouse & N/A & 12 & 15 - 19 Months & 3 Weekst \\
\hline \multirow{7}{*}{$\uparrow$ Angiogenesis } & Morland et al. 2017 & Mouse & Both & 35 & 7 - 9 weeks & 7 Weekst \\
\hline & Slopack et al. 2014 & Mouse & Female & 13 & 9 Weeks & 10 Days \\
\hline & Ding et al. 2006 & Rat & Female & 16 & 22 Months & 3 Weekst \\
\hline & Swain et al. 2003 & Rat & Female & 45 & 5 Months & 30 Days ${ }^{\dagger}$ \\
\hline & Kleim et al. 2002 & Rat & Male & 16 & 5 Months & 30 Days ${ }^{\dagger}$ \\
\hline & Isaacs et al. 1992 & Rat & Female & 38 & 10 Months & 1 Month $t$ \\
\hline & Black et al. 1990 & Rat & Female & 38 & 10 Months & 30 Days ${ }^{\dagger}$ \\
\hline \multirow{4}{*}{$\begin{array}{l}\downarrow \text { CNot Specified Inflammation [or } \\
\text { inflammatory biomarkers] }\end{array}$} & Vieira et al. 2009 & Human & Both & 127 & Mean $=70$ Years & 10 Months ${ }^{\dagger}$ \\
\hline & Kadoglou et al. 2007 & Human & Both & 60 & Mean $=61.64 \pm 4.9$ Years & 6 Months ${ }^{\dagger}$ \\
\hline & Kohut et al. 2006 & Human & Both & 87 & 64 - 87 Years & 10 Months ${ }^{\dagger}$ \\
\hline & Mattusch et al. 2000 & Human & Male & 22 & Mean $=34$ Years & 9 Monthst \\
\hline \multirow[t]{3}{*}{ 个 VO2max } & Dupuy et al. 2015 & Human & Female & 58 & $\begin{array}{l}\text { Means }=24.6 \pm 3.6 \text { and } 62.9 \pm \\
5.4 \text { Years }\end{array}$ & N/A \\
\hline & Voss, Heo et al. 2013 & Human & Both & 70 & Mean $=64.87 \pm 4.46$ Years & 1 Yeart \\
\hline & Pereira et al. 2007 & Human & Both & 11 & Mean $=33$ Years & 3 Monthst \\
\hline \multicolumn{7}{|l|}{ Improved Cerebral Circulation } \\
\hline 个 eNos & Gertz et al. 2006 & Mouse & Male & 16 & $\mathrm{~N} / \mathrm{A}$ & 3 Weekst $^{+}$ \\
\hline \multirow[t]{2}{*}{$\uparrow$ serum VEGF } & Schobersberger et al. 2000 & Human & Male & 13 & Mean $=36.3$ Years & 0 - 5 Days \\
\hline & Asano et al. 1998 & Human & Both & 8 & Mean $=20.4 \pm 0.9$ Years & 10 - 29 Days \\
\hline 个 EPCs & Gertz et al. 2006 & Mouse & Male & 16 & $\mathrm{~N} / \mathrm{A}$ & 23 - 31 Days \\
\hline \multirow{2}{*}{$\uparrow \mathrm{CBV}$} & Maass et al. 2015 & Human & Both & 40 & Mean $=68.4 \pm 4.3$ Years & 3 Months ${ }^{\dagger}$ \\
\hline & Pereira et al. 2007 & Human & Both & 11 & Mean $=33$ Years & 3 Months ${ }^{\dagger}$ \\
\hline \multicolumn{7}{|c|}{ Upregulation of Neurotrophins and Supporting Factors } \\
\hline 个 Hippocampal BDNF Expression & Marlatt et al. 2012 & Mouse & Female & 19 & 9 Months & 8 Monthst \\
\hline
\end{tabular}




\begin{tabular}{|c|c|c|c|c|c|c|}
\hline & Aguiar et al. 2011 & Rat & Female & 35 & 24 Months & 5 Weeks $^{\dagger}$ \\
\hline & Lafenêtre et al. 2010 & Mouse & Female & 38 & 2 - 3 Months & 13 Days ${ }^{\dagger}$ \\
\hline & Chen and Russo-Neustadt 2009 & Mouse & Both & 123 & 3 Months & 6 Hours $^{\dagger}$ \\
\hline & Rasmussen et al. 2009 & Mouse & Male & 40 & N/A & 2 - 6 Hours \\
\hline & Aguiar et al. 2008 & Mouse & Male & 24 & 6 Weeks & 8 Weeks $^{\dagger}$ \\
\hline & Soya et al. 2007 & Rat & Male & 12 & 11 Weeks & 10 Days ${ }^{\dagger}$ \\
\hline & Berchtold et al. 2005 & Rat & Male & $\sim 70$ & $7-8$ Weeks & 14 - 90 Days \\
\hline & Vaynman et al. 2004 & Rat & Male & 28 & 3 Months & 1 Weekt \\
\hline & Johnson et al. 2003 & Mouse & Male & 24 & 8 Weeks & 1 Week \\
\hline & Carro et al. 2000 & Rat & N/A & 18 & N/A & 1 Hourt \\
\hline & Neeper et al. 1995 & Rat & N/A & N/A & $\mathrm{N} / \mathrm{A}$ & 2 - 7 Days \\
\hline \multirow{3}{*}{ 个 PKB Activation } & Aguiar et al. 2011 & Rat & Female & 35 & 24 Months & 5 Weeks $^{\dagger}$ \\
\hline & Chae and Kim 2009 & Rat & Male & 45 & 6 Weeks & 8 Weeks $^{\dagger}$ \\
\hline & Chen and Russo-Neustadt 2005 & Rat & Male & 28 & 3 Months & 2 Weeks ${ }^{\dagger}$ \\
\hline \multirow[t]{3}{*}{ 个 CREB Activation } & Aguiar et al. 2011 & Rat & Female & 35 & 24 Months & 5 Weeks ${ }^{\dagger}$ \\
\hline & Chen and Russo-Neustadt 2005 & Rat & Male & 28 & 3 Months & 2 Weekst \\
\hline & Vaynman et al. 2004 & Rat & Male & 28 & 3 Months & 1 Week $^{\dagger}$ \\
\hline \multicolumn{7}{|l|}{ Brain Plasticity } \\
\hline \multirow{5}{*}{$\begin{array}{l}\text { 个 Neurogenesis (VEGF and 5-HT } \\
\text { dependent) }\end{array}$} & Nokia et al. 2016 & Rat & Male & 28 & $\sim 6$ Months & 7 Weeks $^{\dagger}$ \\
\hline & Chae et al. 2014 & Rat & Male & 96 & 24 Weeks & 2 Days - 6 Months \\
\hline & Klempin et al. 2013 & Mouse & Female & 60 & 6 Weeks - 1 Year & 7 Days $^{\dagger}$ \\
\hline & Marlatt et al. 2012 & Mouse & Female & 19 & 9 Months & 8 Months $^{\dagger}$ \\
\hline & van Praag et al. 1999 & Mouse & Female & 70 & 3 Months & 12 Days - 4 Weeks \\
\hline$\downarrow$ Hippocampal Apoptosis & Chae and Kim 2009 & Rat & Male & 45 & 6 Weeks & 8 Weekst \\
\hline \multirow[t]{6}{*}{$\downarrow$ Age-related white/grey matter loss } & Voss, Heo et al. 2013 & Human & Both & 70 & Mean $=64.87 \pm 4.46$ Years & 1 Yeart \\
\hline & Johnson et al. 2012 & Human & Both & 26 & Mean $=64.8 \pm 2.8$ Years & N/A \\
\hline & Ruscheweyh et al. 2011 & Human & Both & 62 & Mean $=60.2 \pm 6.6$ Years & 6 Months ${ }^{\dagger}$ \\
\hline & Voss et al. 2010 & Human & Both & 152 & $\begin{array}{l}\text { Means }=24.1 \pm 5.1 \text { and } 66.5 \pm \\
5.7 \text { Years }\end{array}$ & N/A \\
\hline & Gordon et al. 2008 & Human & Both & 60 & $\begin{array}{l}\text { Means }=22.5 \pm 2.1 \text { and } 71.5 \pm \\
4.7 \text { Years }\end{array}$ & N/A \\
\hline & Colcombe et al. 2006 & Human & Both & 59 & Mean $=66.5$ Years & 6 Months ${ }^{+}$ \\
\hline \multicolumn{7}{|l|}{ Transient Elevations } \\
\hline 个 BBB permeability & Bailey et al. 2011 & Human & Male & 8 & $35 \pm 7$ years & $1-20$ Minutes \\
\hline
\end{tabular}




\begin{tabular}{|c|c|c|c|c|c|c|}
\hline \multirow[t]{9}{*}{$\uparrow$ Serum BDNF } & Håkansson et al. 2017 & Human & Both & 19 & Mean $=70.8 \pm 0.8$ Years & 35 - 95 Minutes \\
\hline & Marquez et al. 2015 & Human & Male & 8 & Mean $=28 \pm 5$ Years & 10 - 19 Minutes \\
\hline & Schmolesky et al. 2013 & Human & Male & 45 & 18 - 25 Years & 20 - 40 Minutes \\
\hline & Brunelli et al. 2012 & Human & Male & 10 & Mean $=22.0 \pm 0.6$ Years & 35 - 90 Minutes \\
\hline & Griffin et al. 2011 & Human & Male & 47 & Mean $=22 \pm 2$ Years & 60 Minutes \\
\hline & Chen and Russo-Neustadt 2009 & Mouse & Both & 123 & 3 Months & 6 Hourst \\
\hline & Rasmussen et al. 2009 & Human & Male & 8 & 22 - 40 Years & 4 Hours \\
\hline & Ferris et al. 2007 & Human & Both & 15 & Mean $=25.4 \pm 1.01$ Years & 30 Minutes ${ }^{\dagger}$ \\
\hline & Ding, Vaynman et al. 2006 & Rat & Male & 32 & N/A & 5 Days ${ }^{+}$ \\
\hline 个 Neuronal IGF-1 Uptake & Carro et al. 2000 & Rat & N/A & 18 & $\mathrm{~N} / \mathrm{A}$ & 1 Hourt \\
\hline$\uparrow$ Serum VEGF & Schobersberger et al. 2000 & Human & Male & 13 & Mean $=36.3$ Years & 0 - 5 Days \\
\hline \multirow[t]{2}{*}{ 个 Hippocampal VEGF expression } & Morland et al. 2017 & Mouse & Both & 35 & 7 - 9 weeks & 7 Weekst \\
\hline & Tang et al. 2010 & Mouse & N/A & 12 & 6 - 8 weeks & 1 - 2 Hours \\
\hline
\end{tabular}

